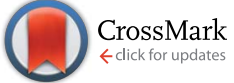

Cite this: RSC Adv., 2016, 6, 36656

Received 1st March 2016

Accepted 2nd April 2016

DOI: $10.1039 / c 6 r a 05498 f$

www.rsc.org/advances

\section{Anhydride-based chemistry on graphene for advanced polymeric materials $\uparrow$}

\author{
Susana Quiles-Díaz, Gerardo Martínez, Marián A. Gómez-Fatou, Gary J. Ellis \\ and Horacio J. Salavagione*
}

Functionalization of graphene based on the coupling of acylium ions under conditions similar to Friedel-Crafts acylation is reported. The reaction is applied to the functionalization of graphene with low molecular weight polypropylene, and the resulting material when incorporated as a filler significantly enhances the electrical, mechanical and thermal performance of a commodity polymer like polypropylene.

The covalent functionalization of graphene is of great importance in many fields, including: electronics, where chemistry induces a band gap on graphene; ${ }^{1}$ touch screens, smart windows or other optical devices, in which graphene combines transparency and conductivity and where chemistry promotes adhesion to plastic or glass substrates; supercapacitors, where the presence of modifying groups influences the capacitance and lifetime of the device; and structural and conducting materials such as polymer nanocomposites, where the chemistry of graphene determines the interaction with the matrices and, consequently, the incorporation of new properties to the polymer (e.g. electrical conductivity). ${ }^{2}$ In the latter case, the covalent incorporation of graphene to polymers leads to substantial improvements in mechanical performance as well as additional functionalities. ${ }^{3}$

Due to its high impact on materials science, the chemistry of graphene has been recently reviewed by several authors. ${ }^{4-6}$ The principal synthetic routes for the functionalization of graphene can be classified into four main groups: the chemistry of graphene oxide, ${ }^{7}$ diazonium coupling, ${ }^{4,6}$ click reactions ${ }^{8,9}$ and other cycloaddition reactions..$^{5,6}$

Anhydrides occupy an important place in organic chemistry due to their wide chemical versatility, and the modification of

Department of Polymer Physics, Elastomers and Energy Applications, Institute of Polymer Science and Technology (ICTP-CSIC), Juan de la Cierva 3, 28006 Madrid, Spain. E-mail: horacio@ictp.csic.es

$\dagger$ Electronic supplementary information (ESI) available: Full experimental details, FTIR, Raman, TGA, DSC and mechanical characterization of all materials. See DOI: 10.1039/c6ra05498f graphene with anhydrides is very interesting because this group is an active and versatile reagent. However, research on anhydride-functionalization of graphene is scarce. To the best of our knowledge, the only example where graphene has been functionalized with anhydrides is the Diels-Alder coupling of graphene with maleic anhydride, ${ }^{10-12}$ a limited cycloaddition reaction requiring unsaturated bonds in the anhydride. A rather more interesting methodology, proposed here, is the opening of cyclic anhydrides in the presence of graphene. In this case the opening of the anhydrides would lead to graphene functionalized with polar carboxylic groups with a broad chemistry, and would avoid strong oxidation and the subsequent detriment to the $\mathrm{sp}^{2}$ network of graphene, an inevitable consequence of the preparation of GO. ${ }^{7}$

Furthermore, cyclic anhydrides are fundamental tools in polymer science because one of the most important families of polymers, the polyolefins, can be functionalized with succinic anhydride by radical reaction with maleic anhydride, ${ }^{13-15}$ and the anhydride-functionalized polymers are habitually and very successfully employed as compatibilizers in polymer matrices that incorporate diverse modifying fillers or nanofillers to obtain high performance materials. ${ }^{16,17}$

Here we report a detailed study on the covalent modification of graphene under the conditions employed for Friedel-Crafts acylation with anhydrides. Although Friedel-Crafts acylation of graphene edges with derivatives of aminobenzoic acid has been reported, ${ }^{18-21}$ the experimental conditions differ from those described here. The use of carboxylic acid anhydrides affords several advantages; they avoid the use of acyl chlorides, there are no by-products and the reactions tend to give high yields. ${ }^{22}$ In our case, the conditions employed lead to the formation of highly electrophilic acylium ions that immediately react with the electron-rich graphene (Scheme 1).

Full experimental details are provided in the ESI. $\dagger$ Succinic acid and graphene grown by chemical vapor deposition (CVD-G) and deposited on a $\mathrm{Si} / \mathrm{SiO}_{2}$ substrate were employed as an initial model to study the coupling between anhydrides and graphene surfaces under typical Friedel-Crafts conditions. 


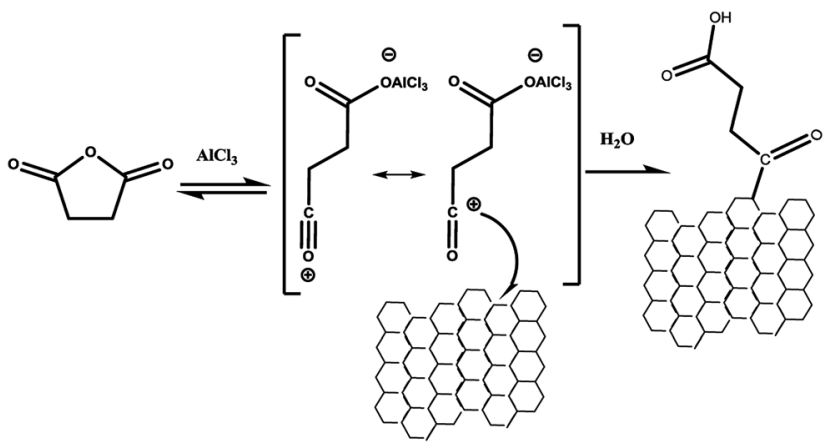

Scheme 1 Synthetic route of succinic anhydride opening and coupling to graphene.

Raman spectroscopy is one of the most powerful techniques for the study of graphene, and can provide important information regarding its covalent functionalization since the introduction of a functional group, particularly on the basal plane, constitutes a defect in the $\mathrm{sp}^{2}$ lattice. ${ }^{23-25}$ Fig. 1 shows the Raman spectra of CVD-G before and after functionalization. The following characteristic features of graphene were observed in the CVD-G before the chemical reaction: the G-band at around $1580 \mathrm{~cm}^{-1}$, corresponding to a doubly degenerate (iTO and LO) phonon mode ( $\mathrm{E}_{2 \mathrm{~g}}$ symmetry) at the Brillouin zone centre, and the second order $2 \mathrm{D}$ band at around $2700 \mathrm{~cm}^{-1}$ (Fig. 1A). ${ }^{26}$ After reaction (mCVD-G) the Raman spectra collected from different areas of the wafer displayed some heterogeneity, with some zones where spectra similar to the original graphene were collected, and others, where important differences were observed that can be related to the experimental conditions employed (see details in ESI $\dagger$ ). In these regions, the spectra show a strong contribution of the disorder-induced $\mathrm{D}$ and $\mathrm{D}^{\prime}$ bands at $1349 \mathrm{~cm}^{-1}$ and $1624 \mathrm{~cm}^{-1}$, respectively, which can be activated by $\mathrm{sp}^{3}$ hybridization both through covalent functionalization $^{23}$ and physical damage. ${ }^{25}$ The latter cause is dismissed in this study because of the gentle experimental conditions employed, and we consider the increase of the $\mathrm{D}$ band to be associated with the covalent modification of the $\mathrm{sp}^{2}$ network. Albeit difficult to assess quantitatively, the intensity ratio of the $\mathrm{D}$ and $\mathrm{G}$ peaks $\left(I_{\mathrm{D}} / I_{\mathrm{G}}\right)$ gives us some qualitative indication of the level of functionalization and its distribution along the graphene monolayer. The $\mathrm{D}$ and $\mathrm{G}$ peaks were deconvoluted (adjusted to Lorentzian curves) and the average $I_{\mathrm{D}} / I_{\mathrm{G}}$ ratio was seen to increase from 0.1 for CVD-G to $>0.7$ for the modified samples. A control experiment with CVD-G and the $\mathrm{AlCl}_{3}$ catalyst (see details in ESI $\dagger$ ) shows an $I_{\mathrm{D}} / I_{\mathrm{G}}$ ratio of 0.13 , confirming that the increase in the $\mathrm{D}$-band arises only from covalent attachment of the opened anhydride moieties. The $I_{\mathrm{D}} / I_{\mathrm{G}}$ band ratio was employed to obtain an image from spectra recorded from a $30 \times 30 \mu \mathrm{m}^{2}$ area where representative changes with respect to the starting graphene were observed, Fig. 1B. Several colored zones with different $I_{\mathrm{D}} / I_{\mathrm{G}}$ ratios can be distinguished in the image, the black and red regions corresponding to those with the lowest and highest values, labeled as (I) and (II) in Fig. 1B, respectively, in the range $I_{\mathrm{D}} / I_{\mathrm{G}} \sim 0.4-0.75$. These results also show that the functionalization is somewhat
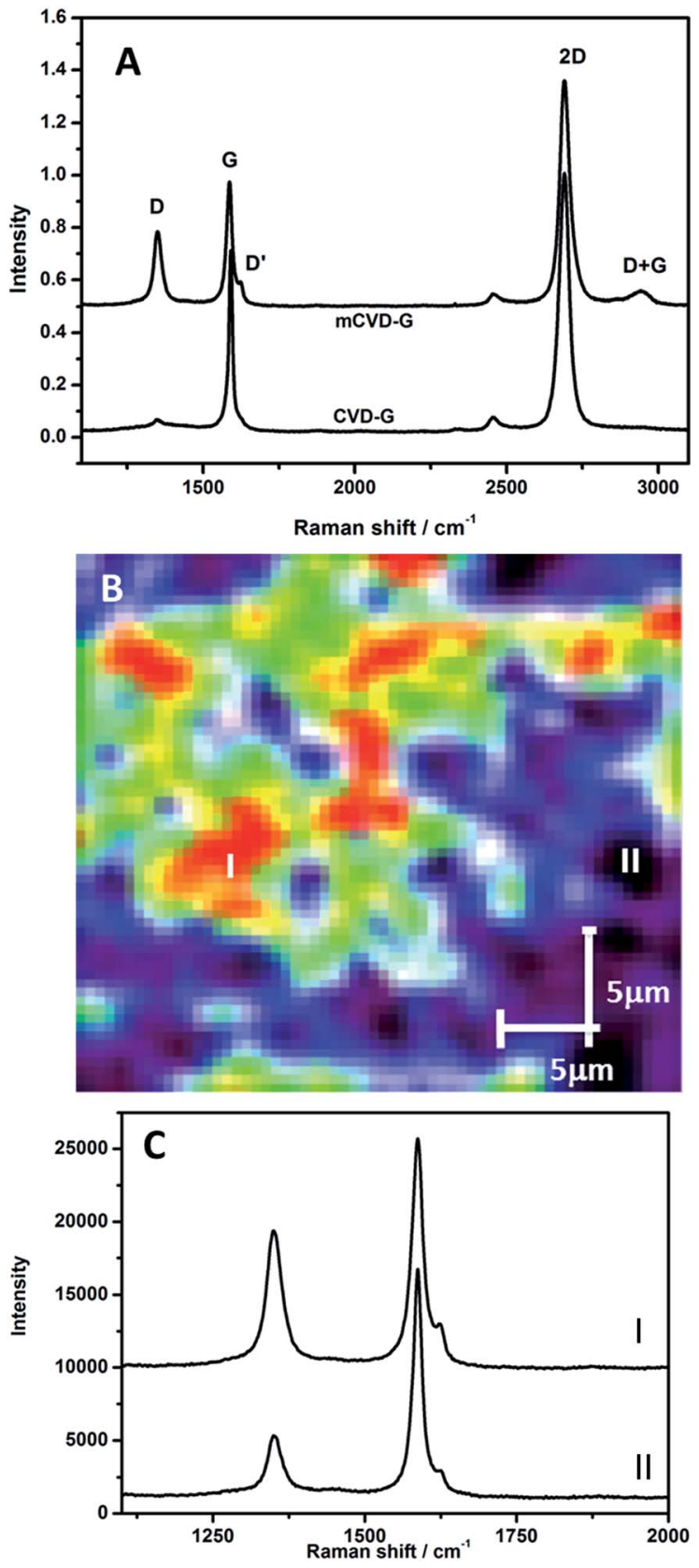

Fig. 1 Raman characterization of CVD-G coupled to acylium ions from succinic acid. (A) Averaged Raman spectra of CVD-G before and after functionalization. (B) $I_{D} / I_{G}$ band ratio image from a $30 \times 30 \mu \mathrm{m}^{2}$ area of $\mathrm{mCVD}-\mathrm{G}$. Representative spectra of both colored zones are shown in (C). $\lambda_{\mathrm{ex}}=514.5 \mathrm{~nm}$.

heterogeneous in its distribution, albeit the degree of modification is reasonable over the whole mapped area. Although FTIR microspectroscopy can complement the study of this system, modifying groups on the surface were not detected due to their low concentration (as explained in ESI $\dagger$ ).

The anhydride opening reaction employed here leads to the presence of polar groups on the graphene surface that will modify its surface properties, which has a direct impact on several potential applications. Graphene is classified as a hydrophobic material and has demonstrated water-repulsion 
properties in hydrophilic polymers. ${ }^{27}$ Despite the fact that the contact angle of graphene surfaces has been shown to be time dependent, ${ }^{28,29}$ in our case the use of water contact angle (WCA) gives a clear estimation of the changes in graphene wettability after functionalization with succinic anhydride (ESI, Fig. S1 $\dagger$ ). The average WCA for CVD-G measured at several points was $85.9^{\circ}$ and falls into the range of experimental and theoretical values for CVD-G on a $\mathrm{Si} / \mathrm{SiO}_{2}$ substrate. ${ }^{29-31}$ After chemical functionalization, the WCA falls markedly and values of between $45.6^{\circ}$ and $62.5^{\circ}$ are obtained. Independently of this fluctuation, undoubtedly due to the heterogeneity in the distribution of the functionalization, it is clear that the functionalization shown in Scheme 1 leads to a remarkable increase in water affinity. After observing that the acylium ion could be successfully coupled to the graphene surface of CVD-G, the same chemical reaction was scaled-up to bulk conditions with polymeric materials. Here graphene nanoplatelets (GNP) were reacted with maleic anhydride grafted polypropylene, PP-MA, (see full experimental details in ESI†). The reaction was accomplished using an excess of polymer in order to confirm the changes in the pendant anhydride groups (anhydride concentration in PP-MA was $\sim 8 \mathrm{wt} \%$ ).
The success of the reaction was confirmed by both Raman and FTIR spectroscopy. The latter shows clear variations in the carboxylic band region 1850-1550 $\mathrm{cm}^{-1}$ (Fig. 2), which confirm the successful opening of the pendant anhydride group in polypropylene. The polymer before reaction, PP-MA, presents characteristic vibrational signatures with bands at $1850 \mathrm{~cm}^{-1}$ and $1782 \mathrm{~cm}^{-1}$ attributed to the asymmetric and symmetric stretching of the $\mathrm{C}=\mathrm{O}$ in anhydride moieties, the band at 1714 $\mathrm{cm}^{-1}$ due to the ester $\mathrm{C}=\mathrm{O}$ stretching vibration, and a weak band centered at $1655 \mathrm{~cm}^{-1}$ originating from an acid $\mathrm{C}=\mathrm{O}$ stretching vibration due to some hydrolysis of the anhydride groups (Fig. 2A). ${ }^{32-35}$ After reacting with graphene, G-PP, the latter band strongly increases in intensity along with the disappearance of the bands due to the anhydride group (1850 and $1752 \mathrm{~cm}^{-1}$ ). In addition a new vibrational mode appears at lower wavelength $\left(\sim 1605 \mathrm{~cm}^{-1}\right)$ that is characteristic of $\mathrm{COO}^{-}$ involved in hydrogen bonds. ${ }^{32}$ Furthermore, other less intense bands due to the $\mathrm{C}-\mathrm{O}-\mathrm{C}$ vibration in anhydrides (around 1225 and $930 \mathrm{~cm}^{-1}$ ) also disappear after the reaction with the GNPs. ${ }^{32,34}$ Raman spectroscopy also confirms the reaction (ESI, Fig. S2 $\dagger$ ). The modified polymer, G-PP, presents the specific bands of polypropylene ${ }^{36}$ and an additional contribution at
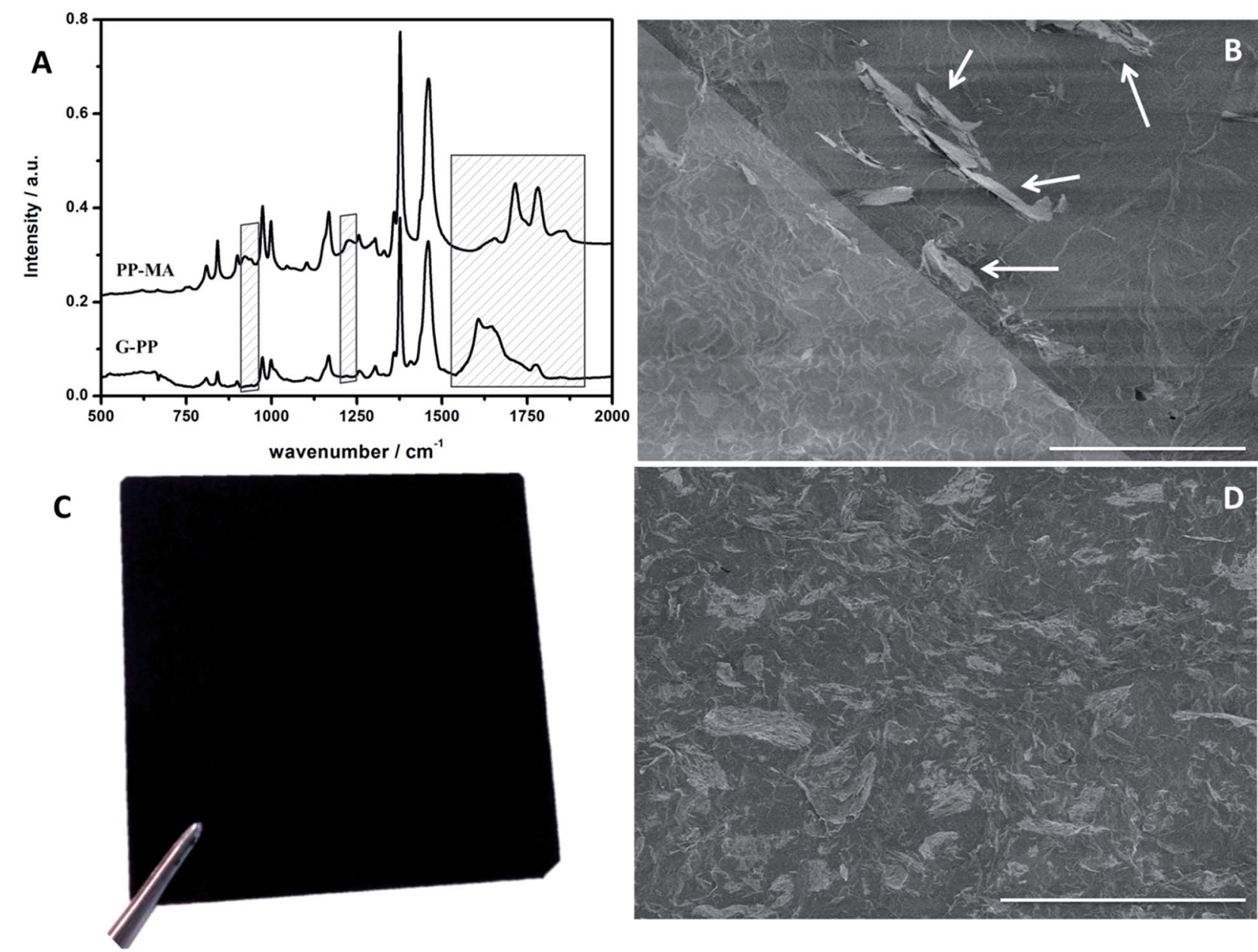

Fig. 2 (A) FTIR spectra of PP-MA and its product by coupling to graphene, G-PP. (B) SEM G-PP, scale bar $=20 \mu \mathrm{m}$. (C) Photography and (D) SEM image of a hot-pressed film of a nanocomposite of iPP with 5 wt\% of G-PP as filler. Scale bar $=50 \mu \mathrm{m}$. 
$1584 \mathrm{~cm}^{-1}$ due to the G-band of graphene (full details of FTIR and Raman bands given in Table S1†). Finally, scanning electron microscopy images of samples prepared by cryo-fracturing hot pressed G-PP show regions where graphene laminates are perfectly dispersed in the matrix (left-hand triangle in Fig. 2B), although some incidence of agglomeration can also be found (see arrows in Fig. 2B).

It is important to point out that the reaction described here for polypropylene is much wider in scope for polymer-based materials. Several polymers that bear pendant anhydride moieties but with very different chemical structure and properties, such as poly(styrene- $b$-ethylene-co-butylene- $b$-styrene) (SEBS), poly(ethylene/vinyl acetate) (PEVA), polyethylene (PE), etc., are commercially available. In this respect, we have succeeded in employing the same reaction for anhydride maleicgrafted poly(vinyl chloride) (PVC), and the complete results are included in the ESI. $\dagger$

Once the coupling of acylium ions from anhydrides to bulk graphene was confirmed, we employed the G-PP as a filler for neat isotactic polypropylene, iPP. It is widely known for polymer nanocomposites that the key factor for obtaining superior properties lies in the strength of the filler/polymer interphase. One interesting strategy to improve this interphase is the modification of the filler with polymer brushes with a similar structure to the matrix. ${ }^{37}$ With this in mind we modified the experimental conditions in order to prepare G-PP materials with much higher quantities of graphene to be used as a filler for iPP, which has important interest for the applications of this commodity polymer.

Fig. 2C shows an $8 \times 8 \mathrm{~cm}^{2}$ hot-pressed film of an iPP/G-PP nanocomposite (see ESI for methodology†). The use of modified graphene, G-PP helps to efficiently disperse the filler into the iPP matrix and graphene islands perfectly distributed throughout the whole polymeric matrix are clearly distinguished (Fig. 2D). These islands of partially wrinkled graphene laminates are around $10-20 \mu \mathrm{m}$ long and of very different thicknesses, ranging from a few nanometers to $5-10 \mu \mathrm{m}$. A nanocomposite with $5 \mathrm{wt} \%$ of G-PP (3.7 wt $\%$ of graphene) imparts electrical conductivity to pristine iPP and enhances its thermal stability (see ESI $\dagger$ ). Thermogravimetric analysis (TGA) shows a remarkable improvement in the thermal stability of iPP with the onset of degradation increased by around $100^{\circ} \mathrm{C}$, and the temperature at which the maximum degradation rate occurs shifted from $469^{\circ} \mathrm{C}$ for iPP to $483.5^{\circ} \mathrm{C}$ for iPP/G-PP (Fig. S5†). Furthermore, this nanocomposite displays a reasonable electrical conductivity, $1.2 \times 10^{-3} \mathrm{~S} \mathrm{~cm}^{-1}$ (details in ESI $\dagger$ ), which is higher than that previously reported for similar compositions. ${ }^{38}$ In addition, the presence of graphene exerts a nucleating effect in the nanocomposite (Fig. S6†) that translates into an improvement in some mechanical properties, e.g. the Young's modulus for the nanocomposites is $\sim 2$ times greater than that of neat iPP (Table S2 $\dagger$ ). Although preliminary, these are very promising results and more experiments are currently underway to fully study this type of materials. Nanocomposites of varying composition and prepared under different processing conditions are currently under evaluation, and the use of these nanocomposites in more complex hierarchical structures is also being addressed. Moreover, the graphene furnished with polymer chains and with carboxylic groups obtained in this work demonstrates a dual role as reinforcement with the potential to be employed as a compatibilizer with many other polymers.

\section{Conclusions}

We have highlighted the impact of the chemistry of cyclic anhydrides in the preparation of graphene-based polymeric materials. In this report we mention the wide scope of this reaction in the field of polymer chemistry. Since succinic anhydride is routinely grafted to diverse polymers in order to improve adhesion and compatibility for very different applications, the exploitation of this approach is of special interest for the preparation of graphene-based polymer nanocomposites. Furthermore, the described strategy provided graphene with carboxylic moieties with broad chemistry for subsequent functionalization reactions. This new approach can provide graphene with an adequate concentration of polar carboxylic groups with a far lower negative impact on the graphene surface quality, avoiding strong oxidation of graphite (to produce GO).

\section{Acknowledgements}

The authors thank the Spanish Government (MINECO) for financial support (Projects: MAT2013-47898-C2-2-R and MAT2014-54231-C4-4P), a Ramon y Cajal Research Fellowship (H. J. S.) and a FPI studentships (S. Q. D). Also Mr David Gómez and Ms Isabel Muñoz (Characterization Service of the Institute of Polymer Science \& Technology) are gratefully acknowledged for the SEM and Raman measurements, respectively.

\section{Notes and references}

1 L. Liao, H. Peng and Z. Liu, J. Am. Chem. Soc., 2014, 136, 12194-12200.

2 M. Castelaín, G. Martínez, C. Marco, G. Ellis and H. J. Salavagione, Macromolecules, 2013, 46, 8980-8987.

3 H. J. Salavagione, G. Martínez and G. Ellis, Macromol. Rapid Commun., 2011, 32, 1771-1789.

4 L. Rodriguez-Perez, M. A. A. Herranz and N. Martin, Chem. Commun., 2013, 49, 3721-3735.

5 C. K. Chua and M. Pumera, Chem. Soc. Rev., 2013, 42, 32223233.

6 S. Eigler and A. Hirsch, Angew. Chem., Int. Ed., 2014, 53, 7720-7738.

7 D. R. Dreyer, S. Park, C. W. Bielawski and R. S. Ruoff, Chem. Soc. Rev., 2010, 39, 228-240.

8 J. L. Segura and H. J. Salavagione, Curr. Org. Chem., 2013, 17, 1680-1693.

9 H. J. Salavagione, J. Mater. Chem. A, 2014, 2, 1738.

10 S. Sarkar, E. Bekyarova and R. C. Haddon, Acc. Chem. Res., 2012, 45, 673-682.

11 S. Sarkar, E. Bekyarova, S. Niyogi and R. C. Haddon, J. Am. Chem. Soc., 2011, 133, 3324-3327.

12 H.-C. Chen, Y.-H. Chen, S.-L. Chen, Y.-T. Chern, R.-Y. Tsai and M.-Y. Hua, Biosens. Bioelectron., 2013, 46, 84-90. 
13 B. G. Soares and R. S. C. Colombaretti, J. Appl. Polym. Sci., 1999, 72, 1799-1806.

14 A. N. Wilkinson, M. L. Clemens and V. M. Harding, Polymer, 2004, 45, 5239-5249.

15 M. Zhang, R. H. Colby, S. T. Milner, T. C. M. Chung, T. Huang and W. deGroot, Macromolecules, 2013, 46, 43134323.

16 Y. Lin, J. Jin and M. Song, J. Mater. Chem., 2011, 21, 34553461.

17 S. Sinha Ray and M. Okamoto, Prog. Polym. Sci., 2003, 28, 1539-1641.

18 I.-Y. Jeon, D. Yu, S.-Y. Bae, H.-J. Choi, D. W. Chang, L. Dai and J.-B. Baek, Chem. Mater., 2011, 23, 3987-3992.

19 K.-S. Kim, I.-Y. Jeon, S.-N. Ahn, Y.-D. Kwon and J.-B. Baek, J. Mater. Chem., 2011, 21, 7337-7342.

20 E.-K. Choi, I.-Y. Jeon, S.-J. Oh and J.-B. Baek, J. Mater. Chem., 2010, 20, 10936-10942.

21 C. K. Chua and M. Pumera, Chem.-Asian J., 2012, 7, 10091012.

22 B. S. Furniss, Vogel's textbook of practical organic chemistry, Pearson Education, India, 1989.

23 S. Niyogi, E. Bekyarova, M. E. Itkis, H. Zhang, K. Shepperd, J. Hicks, M. Sprinkle, C. Berger, C. N. Lau, W. A. deHeer, E. H. Conrad and R. C. Haddon, Nano Lett., 2010, 10, 4061-4066.

24 Z. Jin, T. P. McNicholas, C.-J. Shih, Q. H. Wang, G. L. C. Paulus, A. J. Hilmer, S. Shimizu and M. S. Strano, Chem. Mater., 2011, 23, 3362-3370.

25 L. G. Cançado, A. Jorio, E. H. M. Ferreira, F. Stavale, C. A. Achete, R. B. Capaz, M. V. O. Moutinho,
A. Lombardo, T. S. Kulmala and A. C. Ferrari, Nano Lett., 2011, 11, 3190-3196.

26 A. C. Ferrari, Solid State Commun., 2007, 143, 47-57.

27 A. Flores, H. J. Salavagione, F. Ania, G. Martinez, G. Ellis and M. A. Gomez-Fatou, J. Mater. Chem. C, 2015, 3, 1177-1180.

28 A. Kozbial, Z. Li, C. Conaway, R. McGinley, S. Dhingra, V. Vahdat, F. Zhou, B. D'Urso, H. Liu and L. Li, Langmuir, 2014, 30, 8598-8606.

29 Z. Li, Y. Wang, A. Kozbial, G. Shenoy, F. Zhou, R. McGinley, P. Ireland, B. Morganstein, A. Kunkel, S. P. Surwade, L. Li and H. Liu, Nat. Mater., 2013, 12, 925-931.

30 R. Raj, S. C. Maroo and E. N. Wang, Nano Lett., 2013, 13, 1509-1515.

31 F. Taherian, V. Marcon, N. F. A. van der Vegt and F. Leroy, Langmuir, 2013, 29, 1457-1465.

32 G.-C. Chitanu, L.-I. Zaharia and A. Carpov, Int. J. Polym. Anal. Charact., 1997, 4, 1-20.

33 S. Kawaguchi, M. Kamata and K. Ito, Polym. J., 1992, 24, 1229-1238.

34 E. Peng, J. Ding and J. M. Xue, J. Mater. Chem., 2012, 22, 13832-13840.

35 M. F. Diop and J. M. Torkelson, Polymer, 2013, 54, 41434154.

36 M. Arruebarrena de Báez, P. J. Hendra and M. Judkins, Spectrochim. Acta, Part A, 1995, 51, 2117-2124.

37 M. Castelaín, G. Martínez, G. Ellis and H. J. Salavagione, Chem. Commun., 2013, 49, 8967-8968.

38 K. Kalaitzidou, H. Fukushima and L. T. Drzal, Compos. Sci. Technol., 2007, 67, 2045-2051. 